\title{
Clinical Performance of the Cobalt-Chromium Biodegradable Polymer Coated Sirolimus-Eluting Stent in an Unselected Real-World Population
}

\author{
Prakash Chandwani' ${ }^{1}$, Atul D. Abhyankar², Jayesh S. Prajapati³, Sanjay C. Porwal ${ }^{4}$, \\ Ashok S. Thakkar 5 \\ ${ }^{1}$ Heart and General Hospital, Jaipur, India \\ ${ }^{2}$ Shree B.D. Mehta Mahavir Heart Institute, Surat, India \\ ${ }^{3}$ Apollo Hospitals International Limited, Gandhinagar, India \\ ${ }^{4}$ KLEs Dr. PrabhakarKore Hospital \& Medical Research Centre, Belgaum, India \\ ${ }^{5}$ Sahajanand Medical Tech. Pvt. Ltd., Surat, India \\ Email: chandwanipc@gmail.com
}

Received 16 December 2013; revised 15 January 2014; accepted 14 February 2014

Copyright (C) 2014 by authors and Scientific Research Publishing Inc.

This work is licensed under the Creative Commons Attribution International License (CC BY). http://creativecommons.org/licenses/by/4.0/

\section{Open Access}

\section{Abstract}

OBJECTIVE: The primary objective of the S-CORE registry was to assess the safety and efficacy of the Supralimus-Core ${ }^{\circledR}$ sirolimus-eluting stent deployment for the treatment of coronary artery disease and event-free survival of patients treated with this coronary stent. METHODS: S-CORE Registry is an observational, single-arm, non-randomized, post-marketing surveillance multicenter registry in which 562 patients undergoing single- or multi-vessel percutaneous coronary intervention were enrolled. The pre-specified primary outcome was the rate of major adverse cardiac events (MACE), defined as the composite of cardiac death, myocardial infarction (MI), target lesion revascularisation (TLR) and target vessel revascularisation (TVR) at 12-month post-procedure. Stent thrombosis (ST) served as the safety endpoint. RESULTS: A total of 640 lesions were treated in 562 enrolled patients (mean age $57.4 \pm 10.7$ years) with average stent length of $25.0 \pm 9.0 \mathrm{~mm}$. Stent delivery was successful in $99 \%$ cases. A total of $554(98.6 \%)$ patients have been followed up to 12 months. The incidence of MACE at 30 days and 6 months was $7(1.2 \%)$ and $12(2.1 \%)$ respectively. The composite rate of MACE at a 12-month clinical follow-up was 19 (3.4\%), consisting of $12(2.1 \%)$ cardiac deaths, $0(0 \%)$ MI, $6(1.1 \%)$ TLR and $1(0.2 \%)$ TVR. The long-term follow-up of this registry is going on to confirm safety and efficacy profiles. CONCLUSIONS: This multicenter registry demonstrated satisfactory safety and efficacy profiles, as evidenced by low rates of major adverse cardiac events up to 12 months, for the cobalt-chromium biodegradable polymer-based sirolimus-eluting Supralimus-Core ${ }^{\circledR}$ stent in a "real-world" setting. 


\section{Keywords}

\section{Coronary Artery Disease; Biodegradable Polymer; Sirolimus-Eluting Stent}

\section{Introduction}

Drug eluting stents (DES) significantly reduced the rates of restenosis and target lesion revascularization (TLR) compared with bare metal stents (BMS) in patients with symptomatic coronary artery diseases [1]-[3].

Most of the currently used DES are composed of polymer coating as a drug carrier. However, the permanent presence of these durable polymers has been associated with increased risk of local inflammatory response as well as late and very late thrombosis [4]-[6]. There are multifactorial aetiologies behind late and very late thrombosis. The chronic arterial wall inflammation and hypersensitivity due to the residue of the durable polymer can be considered as one of the aetiologies [7] [8].

Therefore, to overcome the potential drawback of the durable polymer, new generation of DES with a biodegradable polymer has been designed. The first-generation sirolimus-eluting or paclitaxel-eluting stents have a polymer release of antiproliferative drugs from a stainless steel stent platform. More recently, second generation DES have been developed not only to improve long-term DES safety but also to facilitate the procedure by using a cobalt-chromium stent platform [9]-[11]. Cobalt-chromium (Co-Cr) is stronger and more radiopaque than stainless steel, and thus allows strut thickness and total stent volume to be reduced while maintaining radial strength leading to more flexible and deliverable stent platform [12]-[15].

The Supralimus-Core ${ }^{\circledR}$ (Sahajanand Medical Technologies Pvt. Ltd., Surat, India) uses L605 Co-Cr alloy as its stent platform which is coated with a biodegradable polymer to deliver sirolimus. Supralimus-Core ${ }^{\circledR}$ stent system proved its effectiveness by reducing restenosis at 8 months and safety with an acceptable rate of cardiac events at 12 months [16]. The primary objective of the present registry was to assess the safety and efficacy of the Supralimus-Core ${ }^{\circledR}$ sirolimus-eluting stent (SES) deployment for the treatment of coronary artery disease and event-free survival of patients treated with this coronary stent. For this purpose, the occurrence of all major adverse cardiac events (MACE) after stent implantation was assessed in every day practice from the different cardiovascular centres of India.

\section{Methods}

\subsection{Study Design and Patient Population}

S-CORE is an observational, single-arm, non-randomized, post-marketing surveillance multi-center registry conducted at 4 investigational sites in India; designed to validate the performance of Supralimus-Core ${ }^{\circledR}$ SES system in a real-world setting. Between April 2011 and August 2012, 562 patients were enrolled in the registry. The patients, eligible for coronary revascularization with one or more stenotic lesions to be treated with Supralimus-Core ${ }^{\circledR}$ stent in a vessel—having a reference vessel diameter $\geq 2.5 \mathrm{~mm}$ - a site determined visual estimate, were enrolled in the study. The only exclusion criterion was patient's refusal or inability to provide written informed consent. All patients that had at least one Supralimus-Core ${ }^{\circledR}$ SES implanted or attempted were included in the analysis. The study was conducted in accordance with the Declaration of Helsinki and country-specific regulatory requirements. All patients signed informed consent form which was reviewed and approved by the Institutional Review Board or Independent Ethics Committee of each participating centres.

\subsection{Description of the Study Stent}

The Supralimus-Core ${ }^{\circledR}$ (Sahajanand Medical Technologies Pvt. Ltd., Surat, India) has L605 Co-Cr alloy as its stent platform having strut thickness of $60 \mu \mathrm{m}$ with biodegradable polymers and drug load of $1.4 \mu \mathrm{g} / \mathrm{mm}^{2}$. As showed in Figure 1, about 70\% of drug is released within 7 days and remaining drug is released over a period of 48 days.

The coating layer is composed of drug sirolimus together with biodegradable polymeric matrix. This matrix includes different biodegradable polymers-Poly L-Lactide, Poly DL Lactide-co-Glycolide and Polyvinyl Pyr- 


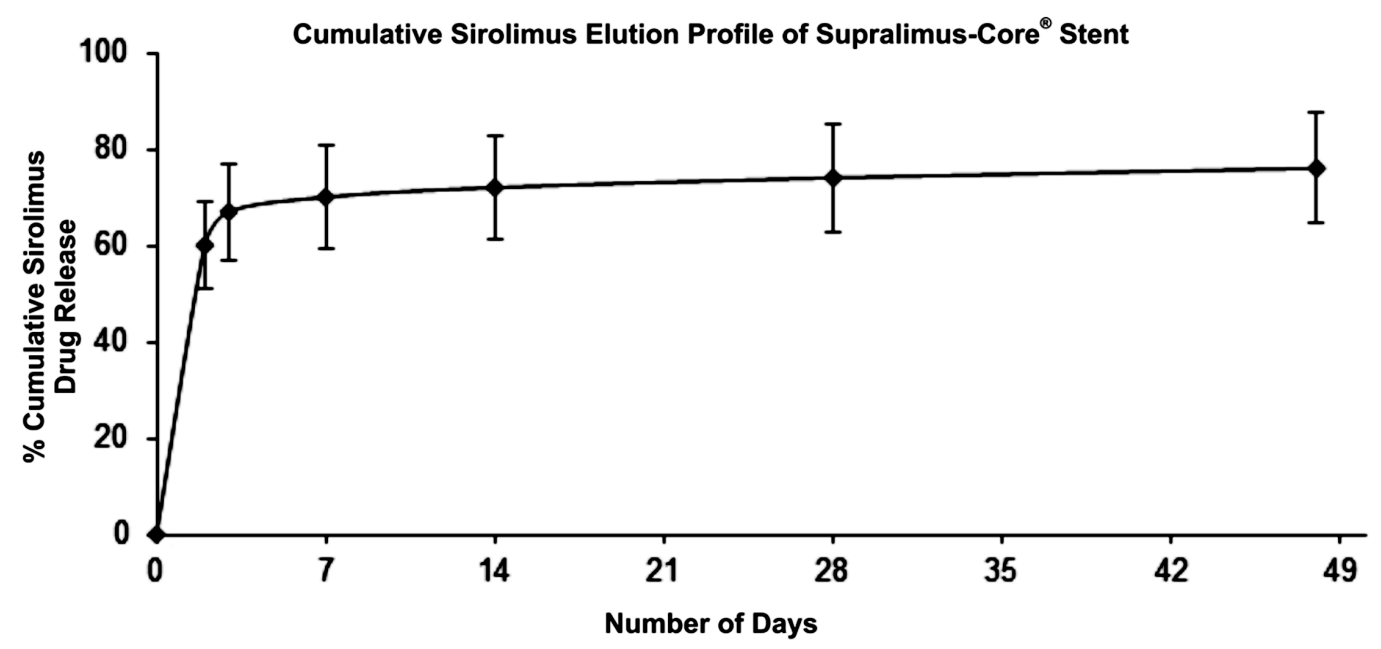

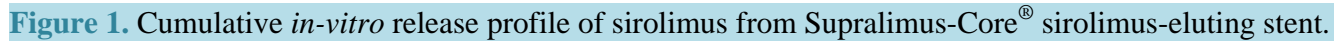

rolidone to control the drug elution from stent coating. The coating of the polymer is conformal around the stent struts and not limited to abluminal surface of the stent. After releasing the drug within 48 days, these polymers eventually degrade naturally and are excreted from the body in the form of their metabolites. The average coating thickness of Supralimus-Core ${ }^{\circledR}$ stent is between 5 to $6 \mu \mathrm{m}$. Scanning electron microscopy images of sterile crimped stents and expanded stents are depicted in Figure 2, showing a smooth and uniform coating surface with minimal-to-no structural defect such as webbing, bridging and strut-to-strut contact, even after expansion of the stent. Supralimus-Core ${ }^{\circledR}$ stent was made available in lengths of 8, 12, 16, 20, 24, 28, 32, 36 and $40 \mathrm{~mm}$ and available diameters were 2.5, 2.75, 3.0 and $3.5 \mathrm{~mm}$.

\subsection{Interventional Procedure and Adjunctive Medications}

The procedures, pre- and post-procedure cardiac enzymes, electrocardiogram and medication regimens (aspirin, clopidogrel, ticlopidine) were according to routine hospital practice. The lesions could be pre-treated with any technique or device such as balloon angioplasty, cutting balloon, or atherectomy, although implantation of Supralimus-Core ${ }^{\circledR}$ stent in each target lesion during the index procedure was mandatory. Antiplatelet therapy with $300 \mathrm{mg}$ of clopidogrel was administered orally within 24 hours before the procedure unless the patient was already taking clopidogrel. An intra-arterial bolus of unfractionated heparin (100 IU/kg) was given to all the patients to achieve an activated clotting time $\geq 250 \mathrm{sec}$ and to initiate the procedure. The administration of procedural glycoprotein IIb/IIIa inhibitors was used according to the operator's discretion. The post-procedural antiplatelet regimen included indefinite aspirin therapy $(75 \mathrm{mg} /$ day) along with clopidogrel orally for 6-months at least.

\subsection{Endpoints of the Registry and Definitions}

The primary endpoint of the study was the incidence of MACE relating to Supralimus-Core ${ }^{\circledR}$ stent at 12-months. In addition, MACE was measured at 30-days, 6, and 12-months and yearly thereafter for two years as secondary endpoints. We defined MACE as a composite of cardiac death, target vessel myocardial infarction (MI), TLR and target vessel revascularization (TVR).

Stent thrombosis was considered as the safety endpoint. According to the definitions proposed by Academic Research Consortium (ARC), we classified stent as definite, probable, and possible [17]; as well as acute ( $\leq 24$ $\mathrm{hr}$ ), subacute ( $24 \mathrm{hr}$ to 30 days), late (30 days to one year), and very late ( $\geq$ one year) thrombosis. If the non-cardiac reason for death of the enrolled patient could not be clearly identified (either through clinical and/or pathological study), the death was considered due to a cardiac origin. The diagnosis of MI was based on either the development of new pathological Q-waves in $\geq 2$ contiguous electrocardiogram leads and/or elevation of creatine kinase myocardial band isoenzyme level more than three times the upper normal limit after the procedure during index hospitalization, or cardiac enzyme level elevation more than two times the upper normal limit 

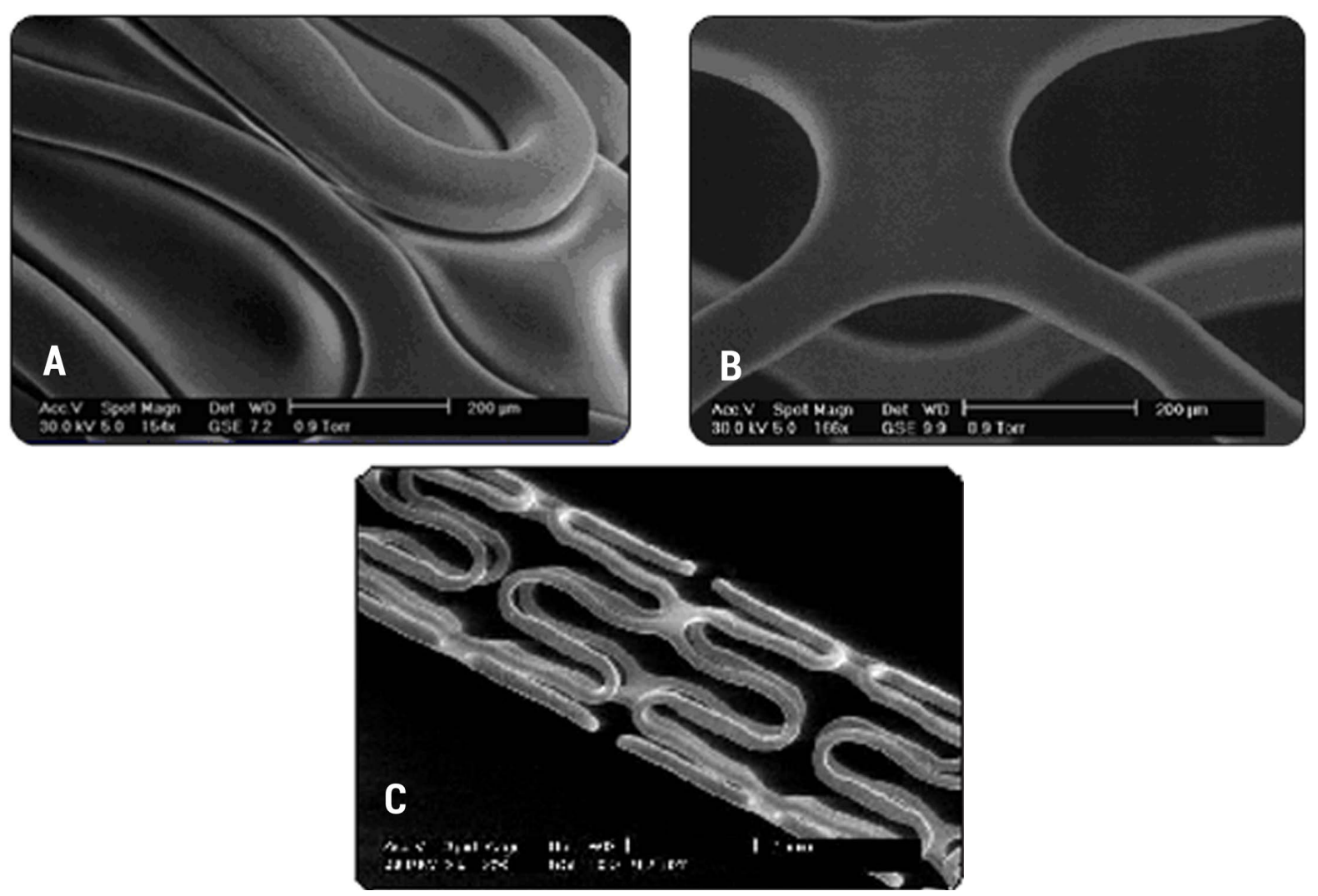

Figure 2. SEM images: (A) Crimped stent; (B) Expanded stent; (C) Normal stent.

thereafter. Any repeat intervention, inside the stent that had been implanted during the index procedure or within the 5-mm proximal or distal segments to the stent, was defined as TLR. TVR was defined as repeat revascularization of the same vessel treated in the index procedure.

\subsection{Data Collection and Follow-Up}

Patients were routinely followed up at 30-days, 6, and 12-months. The clinical follow-up data related to medications and clinical status was prospectively collected on an outpatient basis, by telephone contact, or via their relatives. Cardiologists, general practitioners, and patients were contacted for further information. Some of the data were collected prospectively during follow-up i.e. data related to repeated coronary intervention (surgical and percutaneous) and re-hospitalization. Long term (up to 2-years) follow-up of this registry is still continue to confirm safety and efficacy profiles.

\subsection{Statistical Analysis}

Baseline characteristics of patients were summarized as frequencies and percentages for categorical variables and as means with standard deviations for continuous variables. Kaplan-Meier estimate was used to summarize subcomponents as well as cumulative event-free survival. All data were processed using the Statistical Package for Social Sciences, version 15 (SPSS, Chicago, IL, USA).

\section{Results}

\subsection{Baseline Demographics and Lesion Characteristics}

S-CORE registry comprised 562 patients with 640 lesions. As shown in Table 1, the mean age of all the enrolled patient was $57.4 \pm 10.7$ years, and $479(85.2 \%)$ of patients were male. The registry comprised of patients with diabetes 140 (24.9\%), hypertension 219 (39.0\%) and hypercholesterolemia 177 (31.5\%). Previous MI 
Table 1. Baseline demographics characteristics.

\begin{tabular}{cc}
\hline Characteristics & n = 562 Patients \\
\hline Age (Mean \pm SD, yrs) & $57.4 \pm 10.7$ \\
Male, n (\%) & $479(85.2 \%)$ \\
Diabetes Mellitus, n (\%) & $140(24.9 \%)$ \\
Hypertension, n (\%) & $219(39.0 \%)$ \\
Smoker, n (\%) & $87(15.5 \%)$ \\
Hypercholesterolemia, n (\%) & $177(31.5 \%)$ \\
Family History of CAD, n (\%) & $148(26.3 \%)$ \\
\hline Stable Angina, n (\%) & PCI Indication \\
\hline Unstable Angina, n (\%) & $89(15.8 \%)$ \\
Previous MI, n (\%) & $219(39.0 \%)$ \\
Previous PCI, n (\%) & $49(8.7 \%)$ \\
Previous CABG, n (\%) & $67(11.9 \%)$ \\
Previous Stroke, n (\%) & $12(2.1 \%)$ \\
\hline
\end{tabular}

occurred in 49 (8.7\%) patients and previous percutaneous coronary intervention (PCI) was reported in 67 (11.9\%) patients.

Lesion and procedural characteristics are reported in Table 2. Overall, 233 (36.4\%) lesions were classified as complex (American College of Cardiology/American Heart Association type B2/C). A total of 684 Supralimus-Core ${ }^{\circledR}$ stents were implanted at index procedure (1.22 stents per patients) with an average diameter and total stent length of $3.0 \pm 0.3 \mathrm{~mm}$ and a $25.0 \pm 9.0 \mathrm{~mm}$, respectively. Lesion length was $>20 \mathrm{~mm}$ in 378 (55.3\%) of patients and the reference vessel diameter was $2.5 \mathrm{~mm}$ in 79 (11.5\%) of cases. The overall procedure success rate was $99 \%$.

\subsection{Cumulative MACE during One Year of Follow-Up}

Clinical follow-up was completed in all 554 (98.6\%) patients at 12-months. During the follow-up period, 12 patients died due to cardiac reasons whereas 4 patients died due to non-cardiac reasons. Eight (1.4\%) patients are reported as "lost to follow-up". The primary endpoint, a composite of MACE at 12-months follow-up, occurred in 19 (3.4\%) of 562 patients, consisting of 12 (2.1\%) cardiac deaths, 0 (0.0\%) MI, 6 (1.1\%) TLR and 1 (0.2\%) TVR. The 12-months adverse clinical events are shown in Table 3.

The 12-months MACE-free survival curve and Kaplan-Meier curves of the freedom from cardiac death and TLR are shown in Figures 3 and 4 respectively.

Stent thrombosis according to ARC definitions are stratified in Table 4. Definite late stent thrombosis was observed in $1(0.2 \%)$ patient with a new Q-Wave MI, whereas probable subacute stent thrombosis occurred in 1 (0.2\%) patient, who died at 7 days from the index procedure. Thus, the cumulative incidence of definite or probable stent thrombosis at 12 -months was $2(0.4 \%)$.

\section{Discussion}

DES releasing sirolimus or paclitaxel from durable polymers has been shown to reduce angiographic and clinical measures of restenosis compared with BMS [3] [18]. However, first generation DES have been associated with higher rates of very late stent thrombosis and of restenosis, attributed to delayed healing and delayed re-endothelisation due to the presence of the durable polymer coating [19] [20]. Since permanent polymer coatings may have pro-inflammatory and thrombogenic potential, current DES research has focused on the use of biodegradable polymer coatings which offer the attractive prospect of controlled drug-release without the potential of late polymer-associated adverse effects [21] [22]. The persistent presence of durable polymers leads to long term adverse events. However, biodegradable polymers reduce this risk as they degrade naturally after six to 12-months of the implantation of the stent [23] [24].

Late lumen loss, the risk of angiographic and clinical restenosis can be reduced by a thin-strut design of the 
Table 2. Lesion and procedural characteristics.

\begin{tabular}{|c|c|}
\hline Characteristics & Patients $=562 /$ Lesions $=640$ \\
\hline \multicolumn{2}{|c|}{ Extent of coronary artery disease } \\
\hline 1 Vessel, n (\%) & $261(46.4 \%)$ \\
\hline 2 Vessels, n (\%) & $200(35.6 \%)$ \\
\hline 3 Vessels, n (\%) & $101(18.0 \%)$ \\
\hline \multicolumn{2}{|c|}{ Distribution of lesions } \\
\hline Left anterior descending artery, n (\%) & $368(57.5 \%)$ \\
\hline Right coronary artery, n (\%) & $131(20.5 \%)$ \\
\hline Left circumflex artery, n (\%) & $141(22.0 \%)$ \\
\hline \multicolumn{2}{|c|}{ ACC/AHA lesion classification } \\
\hline A, n (\%) & $213(33.3 \%)$ \\
\hline B1, n (\%) & $194(30.3 \%)$ \\
\hline B2, n (\%) & $175(27.3 \%)$ \\
\hline C, n (\%) & 58 (9.1\%) \\
\hline \multicolumn{2}{|c|}{ TIMI flow pre-procedure } \\
\hline $0 / 1, \mathrm{n}(\%)$ & $240(37.5 \%)$ \\
\hline 2, n (\%) & $68(10.6 \%)$ \\
\hline 3, n (\%) & $332(51.9 \%)$ \\
\hline Total no. of stent, $\mathrm{n}$ & 684 \\
\hline No. of stents per patient, (mean \pm SD, mm) & $1.22 \pm 0.48$ \\
\hline No. of stents per lesion, (mean \pm SD, mm) & $1.07 \pm 0.27$ \\
\hline Average stent length, (mean $\pm \mathrm{SD}$, mm) & $25.0 \pm 9.0$ \\
\hline Average stent diameter, (mean \pm SD, mm) & $3.0 \pm 0.3$ \\
\hline Total occlusion, n (\%) & $143(22.3 \%)$ \\
\hline Long lesions (>20 mm), n (\%) & $378(55.3 \%)$ \\
\hline Small vessels (2.5 mm), n (\%) & 79 (11.5\%) \\
\hline
\end{tabular}

Table 3. Cumulative major adverse cardiac events during 30-days, 6 and 12-months of follow-up $(n=562)$.

\begin{tabular}{cccc}
\hline & 30-days & 6-months & 12-months \\
\hline Death, n (\%) & $7(1.2 \%)$ & $10(1.8 \%)$ & $16(2.8 \%)$ \\
Cardiac death, n (\%) & $7(1.2 \%)$ & $8(1.4 \%)$ & $12(2.1 \%)$ \\
Non-cardiac death, n (\%) & $0(0 \%)$ & $2(0.4 \%)$ & $4(0.7 \%)$ \\
Myocardial infarction, n (\%) & $0(0 \%)$ & $0(0 \%)$ & $0(0 \%)$ \\
TLR, n (\%) & $0(0 \%)$ & $3(0.5 \%)$ & $6(1.1 \%)$ \\
TVR, n (\%) & $0(0 \%)$ & $1(0.2 \%)$ & $1(0.2 \%)$ \\
MACE, n (\%) & $7(1.2 \%)$ & $12(2.1 \%)$ & $19(3.4 \%)$ \\
\hline
\end{tabular}

stainless steel stents [25]-[27]. In the recoil study of Supralimus-Core ${ }^{\circledR}$, in vivo acute stent recoil of Supralimus-Core ${ }^{\circledR}$ showed higher radial strength even though thin strut as compared to other available standard drug-eluting stents [28]. The technical and procedural success of sirolimus-eluting stent as well as late loss and restenosis rate can be improved by the use of Co-Cr as stent platform. Supralimus-Core ${ }^{\circledR}$ stent has a strut thickness of $60 \mathrm{~mm}$ (thin strut) which is also likely to improve long-term angiographic result as shown in MAXIMUS study [16].

Supralimus-Core ${ }^{\circledR}$ stents' clinical effectiveness and safety was initially demonstrated in MAXIMUS study (The first-in-man study of sirolimus-eluting, biodegradable polymer coated Co-Cr Stent). MAXIMUS study used biodegradable polymer as vehicle for sirolimus-eluting Co-Cr stent and it showed excellent procedural success and very low in-hospital MACE. Long-term safety was also well demonstrated at 1-year with low MACE rate (4\%). MAXIMUS study showed in-stent $(0.39 \pm 0.33 \mathrm{~mm})$ and in-segment $(0.33 \pm 0.35 \mathrm{~mm})$ late 


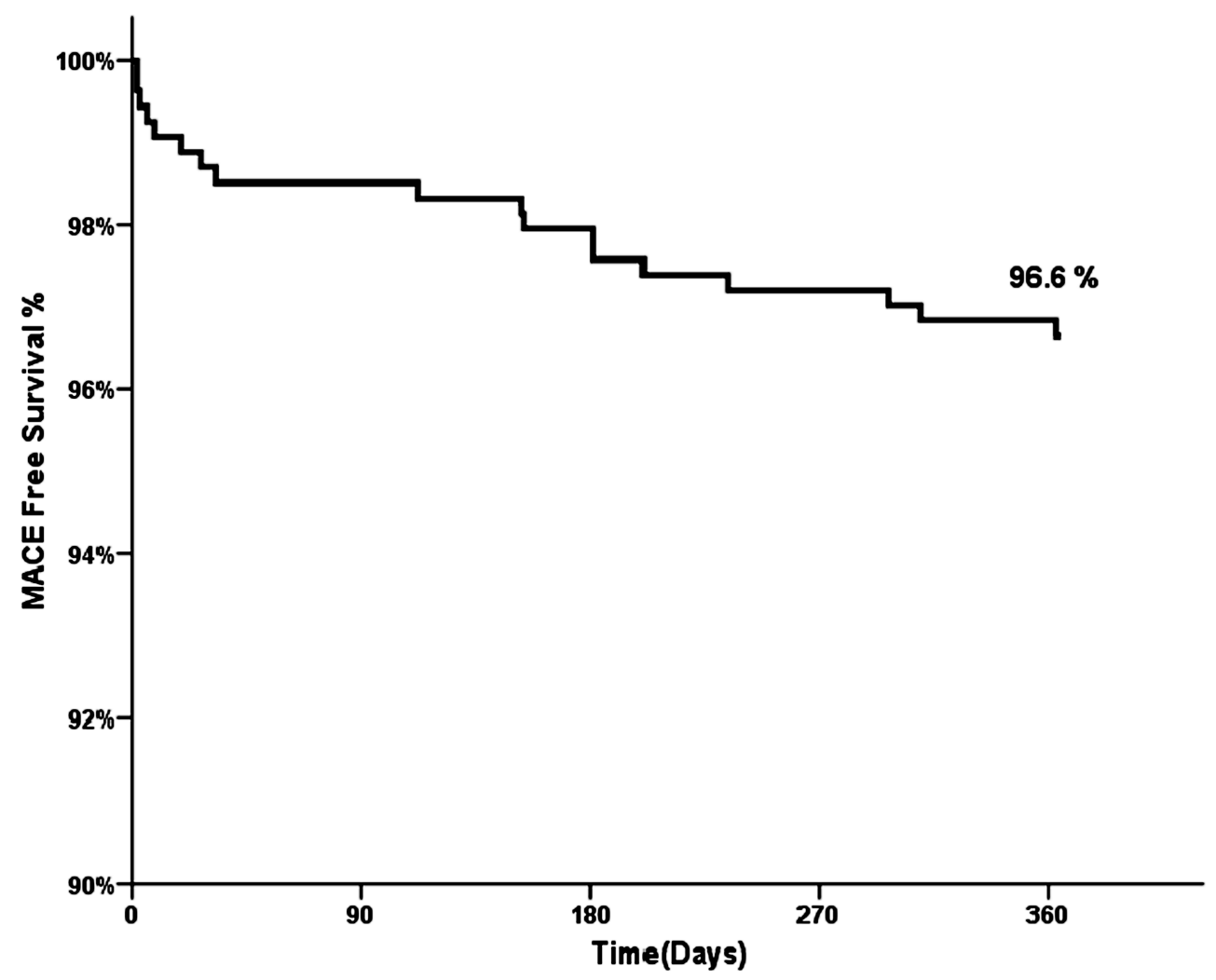

Figure 3. Kaplan-Meier curve of cumulative MACE-free survival over 12-months.

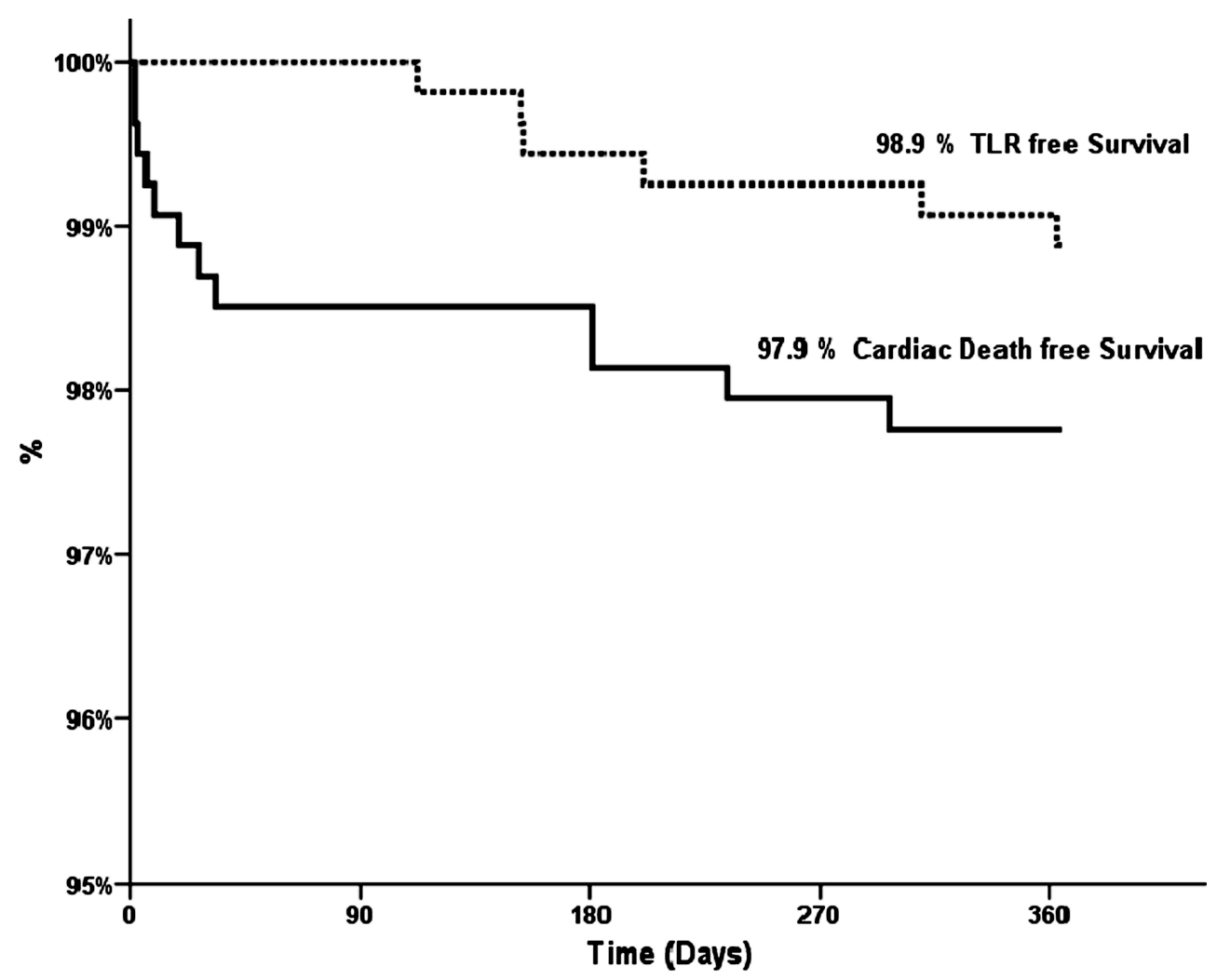

Figure 4. Kaplan-Meier survival curve - cardiac death and target lesion revascularization. 
Table 4. Stent thrombosis during 12 month follow-up according to ARC definitions.

\begin{tabular}{cccc}
\hline & Definite & Probable & Possible \\
\hline Acute ST, n (\%) & $0(0 \%)$ & $0(0 \%)$ & $0(0 \%)$ \\
Subacute ST, n (\%) & $0(0 \%)$ & $1(0.2 \%)$ & $0(0 \%)$ \\
Late ST, n (\%) & $1(0.2 \%)$ & $0(0 \%)$ & $0(0 \%)$ \\
Very late ST, n (\%) & $0(0 \%)$ & $0(0 \%)$ & $0(0 \%)$ \\
Overall ST, n (\%) & $1(0.2 \%)$ & $1(0.2 \%)$ & $0(0 \%)$ \\
\hline
\end{tabular}

loss which is comparatively higher late-loss and can be explained by complex demographic factors of the study population i.e. diabetes (37\%), hypertension (48\%), type-C lesion (6.7\%), >28 mm lesion (20\%) and small vessel-3 mm (<84\%) [16]. S-CORE registry used biodegradable polymer as vehicle for sirolimus-eluting Co-Cr stent showed very low MACE rates (3.4\%) at 12-months.

The potential clinical advantage of a biodegradable polymer might be expected to emerge once the polymer has dissolved. Findings from a recent Supralimus-Core ${ }^{\circledR}$ optical coherence tomography (OCT) study showed 97.21\% strut covered with neointima, and late acquired malapposition was not found at 4-months after Supralimus-Core ${ }^{\circledR}$ implantation [29]. Results of this study suggest that after implantation of the stents with a sirolimus-coated biodegradable polymer, the stented segment is better covered with functional endothelium than first-generation DES, therefore to avoid in-stent restenosis and to minimize risk of stent thrombosis. In this registry, we found $1.1 \%$ target lesion revascularisation and $0.4 \%$ stent thrombosis at 12 -months follow-up.

The present report describes 12-month data from the real-world S-CORE registry of the Co-Cr Supralimus-Core ${ }^{\circledR}$ SES. These results, obtained from four cardiovascular centres in India, provide compelling evidence for the safe and effective use of the Supralimus-Core ${ }^{\circledR}$ SES in routine clinical practice. Despite the high proportion of patients with high-risk characteristics and complex lesions that are usually excluded from randomised trials, Supralimus-Core ${ }^{\circledR}$ stent was associated with a very low incidence of MACE (3.4\%) and stent thrombosis (0.4\%) during a 12-month follow-up.

\section{Conclusion}

These 12-month clinical outcomes from the registry clearly provide the evidence for the safe and effective use of Supralimus-Core ${ }^{\circledR}$ SES in unselected real-world population. Despite the higher risk factor profile and more complex lesion characteristics, the occurrence of late stent thrombosis was very low.

\section{Study Limitations}

There are several limitations of this study. First, it was not a randomised study and that's why limits the possibility of direct comparison with other DES. In order to confirm the efficacy and safety of biodegradable polymer-based SES, head to head comparison with other DES is necessary. Second limitation of the study is the midterm follow-up period. An actual rate of restenosis can be truly estimated if we carry out longer term follow up in a larger cohort of patients which was not in our case.

\section{Conflict of Interest}

Dr. Ashok Thakkar is an employee of Sahajanand Medical Technologies Private Limited. The other authors have no conflicts of interest to declare.

\section{References}

[1] Morice, M.C., Serruys, P.W., Sousa, J.E., Fajadet, J., Ban Hayashi, E., Perin, M., Colombo, A., Schuler, G., Barragan, P., Guagliumi, G., Molnar, F. and Falotico, R. (2002) A Randomized Comparison of a Sirolimus-Eluting Stent with a Standard Stent for Coronary Revascularization. New England Journal of Medicine, 346, 1773-1780. http://dx.doi.org/10.1056/NEJMoa012843

[2] Stone, G.W., Ellis, S.G., Cox, D.A., Hermiller, J., O’Shaughnessy, C., Mann, J.T., Turco, M., Caputo, R., Bergin, P. and Greenberg, J. (2004) A Polymer-Based, Paclitaxel-Eluting Stent in Patients with Coronary Artery Disease. New England Journal of Medicine, 350, 221-231. http://dx.doi.org/10.1056/NEJMoa032441

[3] Moses, J.W., Leon, M.B., Popma, J.J., Fitzgerald, P.J., Holmes, D.R., O’Shaughnessy, C., Caputo, R.P., Kereiakes, 
D.J., Williams, D.O. and Teirstein, P.S. (2003) Sirolimus-Eluting Stents versus Standard Stents in Patients with Stenosis in a Native Coronary Artery. New England Journal of Medicine, 349, 1315-1323.

http://dx.doi.org/10.1056/NEJMoa035071

[4] Feres, F., Costa, J.R. and Abizaid, A. (2006) Very Late Thrombosis after Drug-Eluting Stents. Catheterization and Cardiovascular Interventions, 68, 83-88. http://dx.doi.org/10.1002/ccd.20692

[5] Pfisterer, M., Brunner-La Rocca, H.P., Buser, P.T., Rickenbacher, P., Hunziker, P., Mueller, C., Jeger, R., Bader, F., Osswald, S. and Kaiser, C. (2006) Late Clinical Events after Clopidogrel Discontinuation May Limit the Benefit of Drug-Eluting Stents: An Observational Study of Drug-Eluting versus Bare-Metal Stents. Journal of the American College of Cardiology, 48, 2584-2591. http://dx.doi.org/10.1016/j.jacc.2006.10.026

[6] Daemen, J., Wenaweser, P., Tsuchida, K., Abrecht, L., Vaina, S., Morger, C., Kukreja, N., Jüni, P., Sianos, G. and Hellige, G. (2007) Early and Late Coronary Stent Thrombosis of Sirolimus-Eluting and Paclitaxel-Eluting Stents in Routine Clinical Practice: Data from a Large Two-Institutional Cohort Study. The Lancet, 369, 667-678. http://dx.doi.org/10.1016/S0140-6736(07)60314-6

[7] Kounis, N.G., Giannopoulos, S., Tsigkas, G.G. and Goudevenos, J. (2012) Eosinophilic Responses to Stent Implantation and the Risk of Kounis Hypersensitivity Associated Coronary Syndrome. International Journal of Cardiology, 156, 125-132. http://dx.doi.org/10.1016/j.ijcard.2011.05.052

[8] Nakazawa, G., Ladich, E., Finn, A.V. and Virmani, R. (2008) Pathophysiology of Vascular Healing and Stent Mediated Arterial Injury. EuroIntervention: Journal of EuroPCR in collaboration with the Working Group on Interventional Cardiology of the European Society of Cardiology, 4, C7-C10.

[9] Patel, M.R. and Holmes Jr, D.R. (2008) Next-Generation Drug-Eluting Stents. JAMA: The Journal of the American Medical Association, 299, 1952-1953. http://dx.doi.org/10.1001/jama.299.16.1952

[10] Lange, R.A., Hillis, L.D., Stone, G., Moses, J., Ellis, S., Trikalinos, T., Alsheikh-Ali, A., Tatsioni, A., Nallamothu, B. and Kent, D. (2010) Second-Generation Drug-Eluting Coronary Stents. New England Journal of Medicine, 362, 1728. http://dx.doi.org/10.1056/NEJMe1001069

[11] Alfonso, F. and Fernandez, C. (2011) Second-Generation Drug-Eluting Stents Moving the Field Forward. Journal of the American College of Cardiology, 58, 26-29. http://dx.doi.org/10.1016/j.jacc.2011.03.013

[12] Kereiakes, D.J., Cox, D.A., Hermiller, J.B., Midei, M.G., Bachinsky, W.B., Nukta, E.D., Leon, M.B., Fink, S., Marin, L. and Lansky, A.J. (2003) Usefulness of a Cobalt Chromium Coronary Stent Alloy. The American Journal of Cardiology, 92, 463-466. http://dx.doi.org/10.1016/S0002-9149(03)00669-6

[13] Hagemeister, J., Baer, F.M., Schwinger, R.H. and Hopp, H.W. (2005) Compliance of a Cobalt Chromium Coronary Stent Alloy-The COVIS Trial. Current Controlled Trials in Cardiovascular Medicine, 6, 17. http://dx.doi.org/10.1186/1468-6708-6-17

[14] Legrand, V., Kelbaek, H., Hauptmann, K.E., Glogar, D., Rutsch, W., Grollier, G., Vermeersch, P., Elias, J. and De Cock, C.C. (2006) Clinical and Angiographic Analysis with a Cobalt Alloy Coronary Stent (Driver) in Stable and Unstable Angina Pectoris. The American Journal of Cardiology, 97, 349-352. http://dx.doi.org/10.1016/j.amjcard.2005.08.051

[15] Burzotta, F., Trani, C., Todaro, D., Mazzari, M.A., Porto, I., De Vita, M., Brugaletta, S., Coroleu, S.F., Niccoli, G. and Leone, A.M. (2009) Outcome of Patients Treated by a Novel Thin-Strut Cobalt-Chromium Stent in the Drug-Eluting Stent Era: Results of the SKICE (Skylor in Real World Practice) Registry. Catheterization and Cardiovascular Interventions, 73, 457-465. http://dx.doi.org/10.1002/ccd.21882

[16] Seth, A., Chandra, P., Chouhan, N.S. and Thakkar, A.S. (2012) A First-In-Man Study of Sirolimus-Eluting, Biodegradable Polymer Coated Cobalt Chromium Stent in Real Life Patients. Indian Heart Journal, 64, 547-552. http://dx.doi.org/10.1016/j.ihj.2012.07.011

[17] Cutlip, D.E., Windecker, S., Mehran, R., Boam, A., Cohen, D.J., van Es, G.-A., Steg, P.G., Morel, M.-A., Mauri, L. and Vranckx, P. (2007) Clinical End Points in Coronary Stent Trials a Case for Standardized Definitions. Circulation, 115, 2344-2351. http://dx.doi.org/10.1161/CIRCULATIONAHA.106.685313

[18] Weisz, G., Leon, M.B., Holmes, D.R., Kereiakes, D.J., Popma, J.J., Teirstein, P.S., Cohen, S.A., Wang, H., Cutlip, D.E. and Moses, J.W. (2009) Five-Year Follow-Up After Sirolimus-Eluting Stent Implantation Results of the SIRIUS (Sirolimus-Eluting Stent in De-Novo Native Coronary Lesions) Trial. Journal of the American College of Cardiology, 53, 1488-1497. http://dx.doi.org/10.1016/j.jacc.2009.01.050

[19] Finn, V., Kolodgie, F.D., Harnek, J., Guerrero, L., Acampado, E., Tefera, K., Skorija, K., Weber, D.K., Gold, H.K. and Virmani, R. (2005) Differential Response of Delayed Healing and Persistent Inflammation at Sites of Overlapping Sirolimus- or Paclitaxel-Eluting Stents. Circulation, 112, 270-278. http://dx.doi.org/10.1161/CIRCULATIONAHA.104.508937

[20] Virmani, R., Guagliumi, G., Farb, A., Musumeci, G., Grieco, N., Motta, T., Mihalcsik, L., Tespili, M., Valsecchi, O. 
and Kolodgie, F.D. (2004) Localized Hypersensitivity and Late Coronary Thrombosis Secondary to a Sirolimus-Eluting Stent Should We Be Cautious? Circulation, 109, 701-705. http://dx.doi.org/10.1161/01.CIR.0000116202.41966.D4

[21] Garg, S. and Serruys, P. (2009) Biodegradable Stents and Non-Biodegradable Stents. Minerva Cardioangiologica, 57, 537.

[22] O’Neill, W.W., Dixon, S.R. and Grines, C.L. (2005) The Year in Interventional Cardiology. Journal of the American College of Cardiology, 45, 1117-1134. http://dx.doi.org/10.1016/j.jacc.2005.01.006

[23] Navarese, E.P., Kubica, J., Castriota, F., Gibson, C.M., De Luca, G., Buffon, A., Bolognese, L., Margheri, M., Andreotti, F. and Di Mario, C. (2011) Safety and Efficacy of Biodegradable vs. Durable Polymer Drug-Eluting Stents: Evidence from a Meta-Analysis of Randomised Trials. EuroIntervention, 7, 985-994. http://dx.doi.org/10.4244/EIJV7I8A155

[24] Garg, S. and Serruys, P.W. (2010) Coronary Stents: Looking Forward. Journal of the American College of Cardiology, 56, S43-S78. http://dx.doi.org/10.1016/j.jacc.2010.06.008

[25] Briguori, C., Sarais, C., Pagnotta, P., Liistro, F., Montorfano, M., Chieffo, A., Sgura, F., Corvaja, N., Albiero, R. and Stankovic, G. (2002) In-Stent Restenosis in Small Coronary Arteries Impact of Strut Thickness. Journal of the American College of Cardiology, 40, 403-409. http://dx.doi.org/10.1016/S0735-1097(02)01989-7

[26] Kastrati, A., Mehilli, J., Dirschinger, J., Dotzer, F., Schühlen, H., Neumann, F.-J., Fleckenstein, M., Pfafferott, C., Seyfarth, M. and Schömig, A. (2001) Intracoronary Stenting and Angiographic Results Strut Thickness Effect on Restenosis Outcome (ISAR-STEREO) Trial. Circulation, 103, 2816-2821. http://dx.doi.org/10.1161/01.CIR.103.23.2816

[27] Pache, J., Kastrati, A., Mehilli, J., Schühlen, H., Dotzer, F., Hausleiter, J., Fleckenstein, M., Neumann, F.-J., Sattelberger, U. and Schmitt, C. (2003) Intracoronary Stenting and Angiographic Results: Strut Thickness Effect on Restenosis Outcome (ISAR-STEREO-2) Trial. Journal of the American College of Cardiology, 41, 1283-1288. http://dx.doi.org/10.1016/S0735-1097(03)00119-0

[28] Abhyankar, A. and Thakkar, A.S. (2012) In Vivo Assessment of Stent Recoil of Biodegradable Polymer-Coated Cobalt-Chromium Sirolimus-Eluting Coronary Stent System. Indian Heart Journal, 64, 541-546. http://dx.doi.org/10.1016/j.ihj.2012.07.005

[29] Abhyankar, A., Prajapati, J. and Reddy, S. (2013) Early Vascular Healing with Biodegradable Polymer Coated Sirolimus-Eluting Coronary Stent Implantation: Assessed by Optical Coherence Tomography Results at 4-Month Follow-Up. Minerva Cardioangiologica, 61, 313-322. 